\title{
KAJIAN PENGGUNAAN CUBICOST UNTUK PEKERJAAN QUANTITY TAKE OFF PADA PROSES TENDER
}

\author{
Ajeng Ayu Anindya $a^{1}$, Onnyxiforus Gondokusumo² \\ ${ }^{1}$ Program Studi Magister Teknik Sipil, Universitas Tarumanagara \\ Email: ajenganindya@gmail.com \\ ${ }^{2}$ Program Studi Magister Teknik Sipil, Universitas Tarumanagara \\ Email: onnyxiforusg@ft.untar.ac.id
}

Masuk: 08-01-2020, revisi: 20-01-2020, diterima untuk diterbitkan: 21-01-2020

\begin{abstract}
ABSTRAK
Durasi proses tender yang singkat menyebabkan waktu untuk melakukan pekerjaan quantity take off besi juga singkat. Hal ini menyebabkan perlu adanya inovasi untuk membantu mempercepat pekerjaan quantity take off besi pada proses tender. Perkembangan teknologi saat ini dapat dimanfaatkan untuk membantu mempercepat pekerjaan quantity take off, salah satunya adalah Building Information Modelling (BIM). Salah satu BIM yang dapat digunakan untuk melakukan pekerjaan quantity take off besi adalah Take Off for Rebar (TRB) yang diproduksi oleh perusahaan Cubicost. Penggunaan Cubicost TRB saat ini masih sering ditemukan kendala, namun kendala tersebut dapat diantisipasi dengan melakukan analisis. Analisis dilakukan untuk mengidentifikasi kemungkinan kendala yang timbul, antara lain: pembuatan prosedur kerja, analisis kebutuhan waktu, analisis perbandingan hasil serta analisis keunggulan dan kendala dalam penggunaan Cubicost TRB. Data analisis diperoleh dari melakukan wawancara, penyebaran kuesioner dan melakukan pekerjaan quantity take off besi dengan menggunakan Cubicost TRB dan Metode Konvensional. Dari penelitian yang dilakukan, maka diperoleh hasil bahwa penggunaan Cubicost TRB dapat direkomendasikan, karena selain mempercepat waktu pekerjaan menjadi hanya $58 \%$ dibandingkan dengan metode konvensional, responden juga menyatakan lebih menyukai penggunaan Cubicost dibandingkan dengan metode konvensional. Hal ini dinilai berdasarkan kebutuhan waktu, akurasi, dan cara pengoperasian media hitung. Dalam ketiga klasifikasi tersebut, Cubicost memperoleh nilai rata-rata 8,31 dibandingkan dengan metode konvensional yang hanya mendapatkan nilai rata-rata 6,81. Penelitian ini juga menunjukan bahwa masih terdapat perbedaan dalam perhitungan pekerjaan quantity take-off menggunakan Cubicost TRB dan metode konvensional, walaupun persentasenya kurang lebih hanya sekitar $3 \%$.
\end{abstract}

Kata Kunci: Building Information Modelling (BIM); Cubicost TRB; quantity take off

\begin{abstract}
The short duration of the tender process causes the time to do quantity take off for rebar is also short. This needs innovation to speed up the quantity take off for rebar in the tender process. The technological developments can be utilized to speed up quantity take off for rebar, one of that is Building Information Modeling (BIM). One of the BIM's that can be used to do quantity takeoff for rebar is "Take Off for Rebar" (TRB) produced by Cubicost company. The use of Cubicost TRB is currently still often found obstacles, but these can be anticipated by conducting analysis. The analysis was carried out to identify the possibility of problems that were encountered, in example: making work procedures, analyzing time requirements, analyzing comparative results and analyzing excellence or constraints in using Cubicost TRB. Data analysis was obtained from interviews, questionnaires and doing quantity take off for rebar using Cubicost TRB and conventional methods. From this study, it can be said that the use of Cubicost TRB can be recommended, because in addition to accelerating the work time to only 58\% compared to conventional methods, respondents also said they preferred using Cubicost compared to conventional methods. This is rated based on the needs of the time, accuracy, and how to operate the calculated media. In all three classifications, Cubicost TRB obtained an average value of 8,31 compared to conventional methods which only received an average value of 6,81. This study also shows that there are still differences in the calculation of quantity takeoff for rebar using Cubicost TRB and conventional methods, although the percentage is only around $3 \%$.
\end{abstract}

Keywords: Building Information Modelling (BIM); Cubicost TRB; quantity take off 


\section{PENDAHULUAN}

\section{Latar Belakang}

Dalam upaya mendapatkan pekerjaan pada sektor jasa konstruksi, selalu diawali dengan proses yang dinamakan pelelangan (tender). Penyeleksian yang ketat pada proses tender menyebabkan para peserta tender memberikan penawaran harga secara bersaing. Peserta tender mempersiapkan nilai penawaran yang mencakup, antara lain: direct cost, indirect cost, metode kerja, rencana K3L, dan lain-lain. Pada proses perhitungan biaya direct cost, perhitungan quantity merupakan hal yang sangat esensial. Umumnya, waktu yang tersedia untuk melakukan perhitungan quantity tender sangat singkat, sehingga diperlukan inovasi dengan memanfaatkan perkembangan teknologi pada era digital. Seiring berkembangnya teknologi yang menuntut inovasi di segala bidang termasuk juga di dunia teknik sipil, maka mulai berkembang sebuah aplikasi yang berbasis Building Information Modelling (BIM). BIM adalah salah satu teknologi di bidang AEC (Architecture, Engineering and Construction) yang mampu melakukan simulasi seluruh informasi di dalam proyek pembangunan ke dalam model 3D (Azhar, 2011).

Cubicost adalah salah satu dari beberapa jenis perangkat lunak yang menjadi bagian dari Building Information Modelling (BIM) untuk pekerjaan quantity take off. Take off for Rebar (TRB) adalah salah satu produk Cubicost yang memiliki fungsi untuk menghitung quantity besi pada sebuah bangunan. Cubicost berbasis di Cina dan merupakan perusahaan IT Cina AEC terkemuka. Sesuai namanya 'Cubic' mengacu pada bentuk kubus, yang mencerminkan kemampuannya untuk menerapkan BIM sebagai inti core, dan cost mengacu pada kemampuan memberikan solusi biaya untuk klien di industri AEC. Cubicost menawarkan 4 (empat) jenis produk perangkat lunak berbasis BIM, yaitu Cubicost Take off for Architecture and Structure (TAS), Cubicost Tak eoff for Rebar (TRB), Cubicost Take off for Mechanical and Electrical (TME) dan Cubicost TBQ.

Penggunaan Take-off for Rebar (TRB) dalam pekerjaan quantity take off besi dapat membantu mempersingkat waktu pekerjaan. Pada penggunaannya masih ditemukan kendala sehingga, perlu adanya penelitian mengenai keunggulan dan kendala yang dirasakan para pengguna guna menghindari kesalahan berulang. Tujuan dari penelitian ini, antara lain:

1. Merumuskan prosedur kerja pekerjaan quantity take off

2. Membandingkan waktu yang dibutuhkan

3. Membandingkan hasil perhitungan

4. Mengidentifikasi keunggulan dan kendala

\section{METODE PENELITIAN}

Metode yang digunakan pada penelitian kali ini adalah metode kuantitatif. Metode kuantitatif dipilih karena penelitian dilakukan secara sistematis, terstruktur, serta terperinci. Data yang dibutuhkan pada penelitian adalah data primer. Data primer yang dilakukan adalah wawancara dengan peserta penel untuk mengetahui keunggulan dan kendala dalam penggunaan Cubicost TRB serta melakukan diskusi untuk mendapatkan prosedur kerja yang sesuai untuk pekerjaan quantity take off. Melakukan simulasi pekerjaan quantity take off dengan menggunakan Cubicost TRB dan metode konvensional.

\section{Prosedur Kerja}

Prosedur kerja disiapkan sebelum pekerjaan dimulai guna mengetahui urutan pekerjaan agar dapat diselesaikan sesuai dengan pekerjaan tersebut. Pembuatan prosedur kerja juga harus disesuaikan dengan tujuan pencapaian mutu dan job description dari masing-masing pekerja. Prosedur kerja metode konvensional dibuat dengan referensi buku manual pekerjaan quantity 
take off yang dimiliki PT XYZ dan diskusi dengan quantity surveyor pada 5 kontraktor lainnya. Prosedur kerja dengan menggunakan Cubicost TRB dibuat oleh peneliti berdasarkan pengalaman peneliti dan diskusi dengan pengguna Cubicost dari 5 kontraktor lainnya. Prosedur kerja dimulai dari proses terima gambar tender sampai dengan diperoleh kebutuhan besi untuk masing-masing elemen struktur.

\section{Kebutuhan Waktu}

Untuk mengetahui kebutuhan waktu pekerjaan quantity take off besi dengan menggunakan metode konvensional dan Cubicost TRB, dilakukan simulasi menghitung 1 lantai bangunan gedung perkantoran dengan luasan $2.660,93 \mathrm{~m}^{2}$. Simulasi dilakukan oleh 4 orang yang memiliki pengalaman 2-3 tahun bekerja sebagai estimator di salah satu kontraktor swasta di Jakarta (PT XYZ). Pada proses pengambilan data kebutuhan waktu, dicatat waktu mulai dan waktu selesai pekerjaan untuk masing-masing metode. Waktu mulai dicatat dimulai dari memulai input dan waktu selesai dicatat pada saat hasil perhitungan sudah diperoleh untuk penggunaan Cubicost TRB dan MS. Excel pada metode konvensional. Perhitungan dengan menggunakan metode konvensional menggunakan template perhitungan dalam format MS. Excel yang dimiliki PT XYZ. Hasil quantity perhitungan berupa beton, besi dan bekisting pada gedung perkantoran lantai 7 di input pada sebuah Bill of Quantity (BQ).

\section{Kebutuhan Besi}

Terdapat perbedaan hasil pekerjaan quantity take off besi dengan menggunakan Cubicost TRB dan metode konvensional, sehingga diperlukan perhitungan dengan elemen yang sama menggunakan kedua metode tersebut. Untuk mengetahui kebutuhan besi yang dihitung menggunakan metode konvensional dan Cubicost TRB dilakukan dengan pengambilan sampel untuk elemen struktur. Sampel elemen struktur yang diambil adalah 2 kolom, 3 bentang balok dan 1 modul pelat lantai. Perhitungan dimulai dengan membuat template untuk masing-masing elemen struktur (balok, kolom dan pelat lantai). Dengan pembuatan template ini diharapkan mempermudah pengecekan quantity untuk tulangan utama dan sengkang pada elemen struktur tersebut. Masing-masing sampel dihitung dengan menggunakan Cubicost TRB dan MS. Excel, kemudian dicatat kebutuhan besinya.

\section{Identifikasi Keunggulan dan Kendala}

Penggunaan Building Information Modelling (BIM) pada pekerjaan quantity take off dapat mempercepat pekerjaan dan mengurangi sumber daya manusia, namun masih juga ditemukan kendala pada penggunaanya yang dapat menghambat pekerjaan. Keunggulan dan kendala pada pekerjaan quantity take off dengan Cubicost TRB diperoleh berdasarkan pengalaman dari hasil wawancara pengguna Cubicost TRB atau pada penelitian ini disebut peserta panel.

Peserta panel pada penelitian ini adalah 16 orang yang bekerja di kontraktor dan menggunakan Cubicost TRB untuk pekerjaan quantity take off besi pada proses tender. Peserta panel pada penelitian ini berasal dari 3 kontraktor swasta dan 2 kontraktor BUMN di Indonesia. Wawancara dilakukan dengan jumlah pertanyaan sebanyak 30 pertanyaan yang berfokus pada proses input, pengaturan calculation setting dan proses calculate (output). Metode yang digunakan pada penelitian ini adalah metode Delphi. The Delphi Techniques adalah proses kelompok yang digunakan untuk mensurvei dan mengumpulkan pendapat para ahli tentang subjek/objek tertentu. Linestone dan Turoff (1975) memberikan definisi dasar dari Teknik Delphi: "Delphi dapat dikarakteristikan sebagai metode untuk menyusun proses komunikasi kelompok, sehingga proses ini efektif dalam memungkinkan sekelompok individu secara keseluruhan. Teknik ini berguna 
dimana pendapat dan penilaian para ahli dan praktisi diperlukan tetapi waktu, jarak, dan faktorfaktor lain membuatnya tidak mungkin atau tidak mungkin bagi panel untuk bekerja sama dilokasi fisik yang sama".

Langkah pertama dari metode Delphi adalah menentukan kriteria untuk kualifikasi peserta panel untuk memastikan bahwa mereka memiliki pengetahuan dan pengalaman yang cukup dalam teknologi Cubicost TRB. Pada penelitian ini peserta panel (responden) minimal 2 tahun menggunakan Cubicost TRB dan 3 kali melakukan pekerjaan quantity take-off menggunakan Cubicost TRB. Hasil dari wawancara dengan peserta panel dikumpulkan dalam bentuk pendapat (statement) kemudian dijadikan acuan untuk pembuatan kuesioner lanjutan. Kuesioner dalam bentuk pendapat disebarkan kepada 16 peserta panel untuk diberikan nilai dengan skala 1-10. Nilai rata-rata (mean), median, dan standar deviasi $(\sigma)$ dihitung untuk setiap statement yang sudah diberi nilai. Nilai rata-rata dan median adalah ukuran central tendency dan digunakan untuk menentukan peringkat variabel, sedangkan standar deviasi $(\sigma)$ adalah ukuran konsensus kelompok (Hallowell dan Gambatase, 2010 dan Seyis, 2019).

Berdasarkan penilaian untuk masing-masing pendapat, kemudian ditentukan tingkat persetujuan dan tingkat signifikannya. Tingkat persetujuan diperoleh dari nilai rwg yang menunjukkan dari nilai terendah berarti kurangngya persetujuan dan nilai tinggi berarti persetujuan sangat kuat untuk masing-masing pendapat. Tingkat signifikan yang ditentukan berdasarkan nilai rata-rata (mean), untuk mengetahui pendapat tersebut merupakan keunggulan atau kendala.

Pada kegiatan quantity take off dengan menggunakan Cubicost TRB dan metode konvensional terdapat perbedaan. Dengan adanya perbedaan ini, pekerjaan quantity take off dapat diklasifikasikan menjadi kebutuhan waktu kerja, akurasi perhitungan dan cara pengoperasian. Klasifikasi ini dipilih berdasarkan kebutuhan untuk melakukan pekerjaan quantity take off besi pada proses tender. Oleh karena itu, dilakukan penyebaran kuesioner kembali untuk mengetahui keunggulan berdasarkan pengalaman pengguna Cubicost TRB dan metode konvensional pada pekerjaan quantity take off. Responden yang ikut serta dalam pemberian nilai ini berjumlah 10 orang dari departemen estimate PT XYZ.

Masing-masing klasifikasi memiliki bobot yang berbeda-beda sesuai dengan kebutuhannya. Menetapkan bobot adalah proses yang penting untuk kriteria evaluasi karena berbagai alasan perubahan dalam rentang variasi untuk setiap kriteria evaluasi, dan tingkat kepentingan yang berbeda yang melekat pada rentang variasi ini (Al-Anbari dan Thameer, 2015). Pertimbangan pembobotan tersebut dapat dianalisa menggunakan metode pairwise comparison dengan skala 14. Metode ini dikembangkan oleh Saaty (1980), dalam konteks proses hirarki analitik (Analytic Hierarchy Process). Pairwise comparison dilakukan oleh 4 orang estimator dari departemen estimate PT XYZ. Responden selanjutnya memberikan nilai dengan skala 1-10 berdasarkan pengalaman pengguna Cubicost TRB dan metode konvensional pada pekerjaan quantity take off besi saat proses tender untuk masing-masing klasifikasi. Pemberian nilai tersebut untuk mengetahui metode yang membutuhkan waktu singkat, akurasi perhitungan tinggi dan cara pengoperasian mudah. 


\section{HASIL DAN PEMBAHASAN}

\section{Prosedur Kerja}

Tabel di bawah ini menunjukkan prosedur kerja pekerjaan quantity take off besi dengan metode konvensional dan Cubicost TRB di PT XYZ. Dari tabel tersebut menunjukkan bahwa prosedur kerja dengan menggunakan Cubicost TRB memiliki langkah yang lebih sedikit dibandingkan dengan metode konvensional. Hal ini membuktikan bahwa teknologi dapat meminimalkan langkah kerja, sehingga pekerjaan dapat lebih cepat.

Tabel 1. Tabel prosedur kerja pekerjaan quantity take off dengan metode konvensional dan Cubicost TRB di PT XYZ

Sumber: Penulis, 2019

Proses Pekerjaan Quantity Take off Besi oleh Estimator

Konvensional (MS. Excel)

Cubicost TRB

\begin{tabular}{|c|c|c|c|}
\hline 1 & Memeriksa kelengkapan gambar & 1 & Memeriksa kelengkapan gambar \\
\hline 2 & $\begin{array}{l}\text { Memahami std. detail dan memeriksa } \\
\text { gambar-gambar yang memiliki detail } \\
\text { khusus }\end{array}$ & 2 & $\begin{array}{l}\text { Memahami standar detail dan memeriksa } \\
\text { gambar-gambar yang memiliki detail } \\
\text { khusus }\end{array}$ \\
\hline 3 & $\begin{array}{l}\text { Membuat template perhitungan untuk } \\
\text { masing-masing elemen struktur (balok, } \\
\text { kolom, pelat) }\end{array}$ & 3 & Input informasi data proyek ke TRB \\
\hline 4 & $\begin{array}{l}\text { Input data (bend, hook, ld, ldh) ke } \\
\text { template perhitungan }\end{array}$ & 4 & import gambar (CAD) ke TRB \\
\hline 5 & tarik garis polyline di Cad (as ke as) & 5 & Membuat AXIS, AS di TRB \\
\hline 6 & $\begin{array}{l}\text { gunakan "lengh info }(\mathrm{LI}) \text { " untuk } \\
\text { mengetahui panjang elemen yang akan } \\
\text { dihitung }\end{array}$ & 6 & $\begin{array}{l}\text { Membut elemen struktur (kolom, dinding, } \\
\text { balok, dan pelat lantai) dengan informasi } \\
\text { tulangan utama dan tulangan sengkang }\end{array}$ \\
\hline 7 & Copy panjang elemen dari CAD & 7 & $\begin{array}{l}\text { Gambar elemen struktur yang sudah } \\
\text { dibuat ke "Draw" di Cubicost. } \\
\text { Menggambar elemen struktur secara } \\
\text { bersamaan dimulai dari kolom, balok dan } \\
\text { pelat pada satu file TRB. }\end{array}$ \\
\hline 8 & Paste panjang elemen ke MS. Excel & 8 & $\begin{array}{l}\text { Input aturan perhitungan struktur di } \\
\text { "Calculation Rule" }\end{array}$ \\
\hline 9 & $\begin{array}{l}\text { Input data pengurang beton (contoh: } \\
\text { tebal pelat, dimensi kolom kanan-kiri) }\end{array}$ & 9 & Calculate Program, perhitungan selesai. \\
\hline 10 & $\begin{array}{l}\text { Input data tulangan utama (dimeter dan } \\
\text { jumlah tulangan) }\end{array}$ & 10 & $\begin{array}{l}\text { Untuk menampilkan hasil perhitungan, } \\
\text { menggunakan fitur "view quantity by } \\
\text { category" }\end{array}$ \\
\hline 11 & $\begin{array}{l}\text { Input data tulangan sengkang (dimeter } \\
\text { dan sengkang) }\end{array}$ & & \\
\hline 12 & Input data untuk overlap besi $12 \mathrm{~m}$ & & \\
\hline 13 & $\begin{array}{l}\text { Perhitungan selesai, } \\
\text { Perhitungan balok, kolom dan pelat } \\
\text { harus dilakukan secara bergantian } \\
\text { dengan menggunakan template yang } \\
\text { berbeda. }\end{array}$ & & \\
\hline
\end{tabular}




\section{Kebutuhan Waktu}

Tabel 2. Hasil kebutuhan waktu pekerjaan quantity take off besi

Sumber: Penulis, 2019

\begin{tabular}{cccc}
\hline \multirow{2}{*}{ No } & \multirow{2}{*}{ Nama } & \multicolumn{2}{c}{ Kebutuhan Waktu } \\
\cline { 3 - 4 } & & Metode Konvensional & Cubicost TRB \\
\hline 1 & DAR & 6 jam 18 menit & 2 jam 7 menit \\
\hline 2 & GBK & 6 jam 15 menit & 2 jam 30 menit \\
\hline 3 & WIL & 5 jam 15 menit & 2 jam 15 menit \\
\hline 4 & KAR & 5 jam 45 menit & 3 jam 1 menit \\
\hline \multicolumn{2}{c}{ Rata-rata waktu: } & $\mathbf{5}$ jam 54 menit & $\mathbf{2}$ jam 29 menit \\
\hline
\end{tabular}

Tabel di atas menunjukaan rata-rata kebutuhan waktu untuk pekerjaan menggunakan metode konvensional adalah 5 jam 54 menit dan kebutuhan waktu dengan menggunakan Cubicost TRB adalah 2 jam 29 menit. Menggunakan Cubicost TRB lebih cepat 58\% dibandingkan dengan menggunakan metode konvesional dalam pekerjaan quantity take off besi.

\section{Kebutuhan Besi}

Perbandingan hasil yang diperoleh dari pekerjaan quantity take off besi dengan menggunakan Cubicost TRB dan metode konvensional dilakukan dengan cara menghitung masing-masing 1 elemen struktur (balok, kolom dan pelat) dengan menggunakan kedua metode tersebut.

Tabel 3. Perbandingan kebutuhan besi kolom

Sumber: Penulis, 2019

\begin{tabular}{cccc}
\hline \multicolumn{3}{c}{ Kolom } \\
\hline Tipe Kolom & $\begin{array}{c}\text { Cubicost TRB } \\
(1)\end{array}$ & $\begin{array}{c}\text { Metode Konvensional } \\
(2)\end{array}$ & $\begin{array}{c}\text { Persentase } \\
((1)-(2) /(1)) \times 100 \%\end{array}$ \\
\hline K1(basement) & $851,375 \mathrm{~kg}$ & $814,92 \mathrm{~kg}$ & $4,2 \%$ \\
\hline K2 (lantai 7) & $582,726 \mathrm{~kg}$ & $562,68 \mathrm{~kg}$ & $3,44 \%$ \\
\hline
\end{tabular}

Selisih tersebut diakibatkan karena jumlah tulangan utama yang masuk ke pilecap tidak dapat diatur dan jumlah sengkang utama kelebihan 3 buah dengan menggunakan Cubicost TRB. Perbedaan jumlah sengkang dikarenakan perhitungan jumlah sengkang dengan Cubicost TRB menggunakan fitur roundup. Kelebihan jumlah sengkang tidak selalu tiga buah tergantung dengan panjang penyebaran sengkang dan jarak antar sengkang. Kebutuhan besi dengan menggunakan Cubicost TRB lebih banyak dibandingkan dengan menggunakan metode konvensional.

Tabel 4. Perbandingan kebutuhan besi balok Sumber: Penulis, 2019

\begin{tabular}{cccc}
\hline \multicolumn{3}{c}{ Balok } \\
\hline Lokasi Balok & Cubicost TRB & Metode Konvensional & Persentase \\
& $(1)$ & $(2)$ & $((1)-(2) /(1)) \times 100 \%$ \\
\hline AS A-C/3 & $2431,881 \mathrm{~kg}$ & $2414,7 \mathrm{~kg}$ & $0,71 \%$ \\
(lantai 7) & & & \\
\hline
\end{tabular}

Selisih tersebut dikarenakan perhitungan dengan menggunakan Cubicost TRB mempertimbangkan panjang tulangan utama balok yang memiliki perbedaan dimensi dengan balok di sampingnya. Cubicost TRB menghitung secara miring untuk tulangan utama balok yang memiliki beda dimensi dengan balok disampingnya. Kebutuhan besi dengan menggunakan 
Cubicost TRB lebih banyak 0,71\% dibandingkan dengan menggunakna metode konvensional. Kebutuhan besi yang lebih banyak ini memiliki perhitungan yang lebih detail dibandingkan dengan perhitungan menggunakan metode konvenisonal.

Tabel 5. Perbandingan kebutuhan besi pelat lantai Sumber: Penulis, 2019

\begin{tabular}{cccc}
\hline \multicolumn{3}{c}{ Pelat Lantai } \\
\hline Tipe Pelat & $\begin{array}{c}\text { Cubicost TRB } \\
(1)\end{array}$ & $\begin{array}{c}\text { Metode Konvensional } \\
(2)\end{array}$ & $\begin{array}{c}\text { Persentase } \\
((1)-(2) /(1)) \times 100 \%\end{array}$ \\
\hline S2 & $478,156 \mathrm{~kg}$ & $471,13 \mathrm{~kg}$ & $1,4 \%$ \\
\hline
\end{tabular}

Selisih tersebut dikarenakan terdapat kelebihan satu buah jumlah tulangan menerus pada pelat lantai. Kebutuhan besi dengan menggunakan Cubicost TRB lebih besar 1,4\% dibandingkan perhitungan dengan menggunakan metode konvensional. Jumlah tulangan menerus pada pelat lantai yang dihitung dengan Cubicost TRB menggunakan fitur roundup ditambah $1(+1)$.

\section{Identifikasi Keunggulan dan Kendala}

Pengambilan data dilakukan dengan wawancara dan mengirimkan kuesioner ke pengguna Cubicost TRB. Responden yang menjawab kuesioner tersebut merupakan responden yang menggunakan Cubicost TRB untuk pekerjaan quantity take-off besi pada proses tender. Jumlah peserta panel yang terkumpul adalah 16 orang dari 5 kontraktor dengan pengalaman menggunakan Cubicost antara 1-3 tahun. Tabel dibawah ini merupakan jawaban dari wawancara dan penyebaran kuesioner yang berbentuk pendapat responden mengenai penggunaan Cubicost TRB pada proses tender.

Hasil dari wawancara dengan peserta panel dijadikan untuk kuesioner selanjutnya. Kuesioner ini kemudian ditujukan untuk peserta panel agar dapat diberikan penilaian dengan skala 1-10 dengan nilai 1 berarti sama sekali tidak setuju dan 10 berarti sangat setuju sekali. Pemberian ini bertujuan untuk memberikan tingkat persetujuan masing-masing pendapat. Nilai rata-rata (M) digunakan untuk melakukan statistik tingkat signifikansi. Tingkat signifikan yang ditentukan berdasarkan nilai rata-rata (mean), untuk nilai mean $\leq 5,99$ merupakan kendala dan untuk nilai mean $\geq 6$ merupakan keunggulan. Konsensus diantara peserta Delphi dianalisis dan divalidasi oleh statistik IRA. Pengkodean untuk IRA (rwg) diadopsi sebagai berikut (LeBreton dan Senter, 2008).

$0,00 \leq$ rwg $\leq 0,30$ berarti persetujuan kurang

$0,31 \leq \mathrm{rwg} \leq 0,50$ berarti persetujuan lemah

$0,51 \leq \mathrm{rwg} \leq 0,70$ berarti persetujuan sedang (rata-rata)

$0,71 \leq \mathrm{rwg} \leq 0,90$ berarti persetujuan yang kuat

$0,91 \leq \mathrm{rwg} \leq 1,00$ berarti persetujuan yang sangat kuat

Dengan pemberian nilai pada masing-masing pendapat dengan skala 1-10 oleh peserta panel, maka diperoleh kenggulan dan kendala dari penggunaan Cubicost TRB. Jumlah peserta panel yang menjawab kuesioner lanjutan ada 16 orang atau $100 \%$. Pengalaman peserta panel dalam menggunakan Cubicost TRB yang berbeda-beda, maka diperlukan nilai rata-rata atau mean. Berdasarkan nilai mean $\geq 6$ dari data nilai di atas, maka diperoleh keunggulan, antara lain:

a. Syarat untuk menentukan area tumpuan pada kolom, balok dan pelat lantai mudah dipahami karena disertai gambar ilustrasi. 
b. Proses input ties (sengkang tambah) di Cubicost TRB mudah dan terdapat keterangan yang jelas.

c. Tidak ada batasan untuk menggambar elemen berbentuk custom (bukan persegi/ bulat).

d. Tampilan Cubicost TRB mudah dipahami, karena dilengkapi dengan toolbar yang jelas dan menggunakan istilah umum.

e. Menggunakan Cubicost TRB lebih cepat dan mudah dibandingkan dengan metode konvensional (MS. Excel)

f. Langkah-langkah untuk input data (lapis lantai, input gambar CAD, panjang penyaluran, panjang overlap, mutu beton, mutu baja et al) lebih mudah dipahami dengan menggunakan tabel.

g. Pengaturan support beam cukup fleksibel.

h. Tampilan dan notasi pada calculation setting mudah dipahami.

i. Proses merged beam pada saat menggambar elemen balok, dapat mempercepat step kerja.

j. Pada saat menggambar elemen struktur, object snap (titik poin) cukup fleksibel.

k. Fitur other rebars sangat membantu, karena beberapa elemen struktur yang terdapat tulangan tambah dan dapat membantu untuk menggantikan tulangan yang tidak bisa di serap di calculation setting.

1. Pada proses calculate dibutuhkan RAM dan spesifikasi yang tinggi pada komputer atau laptop.

m. Untuk pengaturan menentukan aturan jarak sengkang pada area sambungan untuk balok dan kolom mudah dipahami.

n. Dengan mengikuti training, penggunaan Cubicost TRB menjadi lebih mudah.

o. Langkah perhitungan lebih singkat dibandingkan hitungan konvensional karena tidak ada proses input data (panjang bentang) dari AutoCAD.

p. Menggunakan Cubicost TRB akan mempercepat dan mempermudah jika standar detail konsultan perencana struktur dapat diserap pada calculation setting di TRB.

q. Notasi (/,@,link,TAL,TLL dan lain-lain) yang ditetapkan Cubicost TRB mudah dipahami karena terdapat keterangan untuk setiap notasi.

r. Tampilan 3D membantu mempermudah untuk membayangkan bangunan secara visual.

s. Proses input tulangan ekstra / other rebars dilakukan dengan mudah dan singkat.

t. Langkah-langkah untuk input data (lapis lantai, input gambar CAD, panjang penyaluran, panjang overlap, mutu beton, mutu baja et al) mudah dipahami karena terdapat keterangan tata cara input.

u. Jika terdapat perubahan/ gambar menggunakna Cubicost TRB membutuhkan waktu yang relatif singkat.

Berdasarkan nilai mean $\leq 5.99$ dari data di atas, maka diperoleh kendala, antara lain:

a. Tidak semua standar detail konsultan struktur perencana yang ada di Indonesia dapat diserap oleh Cubicost TRB.

b. Penggunaan Cubicost TRB hanya dapat menerima gambar dengan format AutoCAD sebelun tahun 2007.

c. Perhitungan tangga dan ramp menggunakan Cubicost TRB masih sulit digunakan dan tidak fleksibel.

d. Proses calculate pada Cubicost TRB membutuhkan waktu yang relatif lama.

e. Elemen balok membutuhkan waktu paling banyak dalam proses menggambar di Cubisot TRB.

f. Jenis gambar tulangan balok yang disebar pada gambar denah, membutuhkan waktu yang lama dala pekerjaan quantity take off menggunakan Cubicost TRB. 
g. Cubicost TRB tidak bisa mengatur jumlah tulangan utama kolom dan area penyebaran sengkang kolom yang diteruskan sampai podasi/pilecap.

h. Lokasi sambungan overlap pada balok tidak dapat diatur, hanya mengacu per $12 \mathrm{~m}$ bentang tulangan.

i. Perhitungan pelat lantai yang area tumpuannya dan nilai diameternya dipilih berdasarkan panjang bentang pelat sebelumnya/sesudahnya dengan bentangnya sendiri, kemudian dipilih bentang yang terbesar tidak dapat diatur di Cubicost TRB.

Konsensus diantara peserta panel Delphi dianalisis dan divalidasi oleh statistik IRA ( $r w g$ ). Tingkat persetujuan diperoleh berdasarkan nilai $r w g$, sehingga berdasarkan tabel tersebut dapat disimpulkan bahwa terdapat 1 pendapat dengan persetujuan sangat kuat, 22 pendapat dengan persetujuan kuat, dan 7 persetujuan sedang.

Klasifikasi pada pekerjaan quantity take off dilakukan penilaian untuk memperoleh bobot berdasarkan kebutuhan. Pemberian penilaian ini dilakukan oleh 4 orang yang bekerja selama 2-3 tahun melakukan pekerjaan quantity take off. Penilaian tersebut kemudian dianlisis menggunakan pairwise comparison. Tabel di bawah ini menunjukan hasil penilaian dengan analiais pairwise comparison.

Tabel 6. Hasil Pemberian dengan Analisis Pairwise comparison Sumber: Penulis, 2019

\section{Sumber 1}

\begin{tabular}{|c|c|c|c|c|}
\hline \multicolumn{5}{|c|}{ Pairwise Comparison } \\
\hline & $\mathrm{B}$ & $\mathrm{C}$ & Nilai & Nilai Akhir \\
\hline A & A1 & A1 & 2 & 3 \\
\hline B & & $\mathrm{C} 2$ & 0 & 1 \\
\hline $\mathrm{C}$ & & & 1 & 2 \\
\hline
\end{tabular}

\section{Sumber 2}

\section{Sumber 3}

\begin{tabular}{|c|c|c|c|c|}
\hline \multicolumn{5}{|c|}{ Pairwise Comparison } \\
\hline & $\mathrm{B}$ & $\mathrm{C}$ & Nilai & Nilai Akhir \\
\hline A & A1 & A1 & 2 & 3 \\
\hline B & & $\mathrm{C} 1$ & 0 & 1 \\
\hline $\mathrm{C}$ & & & 1 & 2 \\
\hline
\end{tabular}

\section{Sumber 4}

\begin{tabular}{|c|c|c|c|c|}
\hline \multicolumn{5}{|c|}{ Pairwise Comparison } \\
\hline & $\mathrm{B}$ & $\mathrm{C}$ & Nilai & Nilai Akhir \\
\hline A & B1 & $\mathrm{A} 2$ & 2 & 3 \\
\hline B & & B1 & 2 & 3 \\
\hline $\mathrm{C}$ & & & 0 & 1 \\
\hline
\end{tabular}

\begin{tabular}{|c|c|c|c|c|}
\hline \multicolumn{5}{|c|}{ Pairwise Comparison } \\
\hline & B & $\mathrm{C}$ & Nilai & Nilai Akhir \\
\hline A & A1 & $\mathrm{C} 1$ & 1 & 2 \\
\hline $\mathrm{B}$ & & $\mathrm{C} 1$ & 0 & 1 \\
\hline $\mathrm{C}$ & & & 2 & 3 \\
\hline
\end{tabular}


Tabel 7. Hasil bobot dari pairwise comparison

Sumber: Penulis, 2019

\begin{tabular}{ccccccc}
\hline \multicolumn{7}{c}{ Hasil } \\
\hline & Sumber 1 & Sumber 2 & Sumber 3 & Sumber 4 & Rata-rata & Bobot \\
\hline A & 3 & 3 & 3 & 2 & 2.75 & $44 \%$ \\
\hline B & 1 & 1 & 3 & 1 & 1.5 & $24 \%$ \\
\hline C & 2 & 2 & 1 & 3 & 2 & $32 \%$ \\
\cline { 1 - 1 } & \multicolumn{7}{c}{} & & Total : & $\mathbf{6 . 2 5}$ & $\mathbf{1 0 0 \%}$ \\
\hline
\end{tabular}

Keterangan:

A $=$ Akurasi

$\mathrm{B}=$ Kebutuhan Waktu

$\mathrm{C}=$ Cara Pengoperasian

Berdasarkan perhitungan pairwise comparison yang telah dilakukan, didapatkan bahwa bobot untuk akurasi perhitungan adalah yang paling tinggi (44\%), diikuti cara pengoperasian (32\%), dan terakhir adalah kebutuhan waktu kerja (24\%). Hasil persentase tersebut kemudian akan menjadi bobot pada nilai yang diberikan responden untuk pekerjaan quantity take off dengan menggunakan Cubicost TRB dan metode konvensional.

Tabel 8. Hasil penilaian mengenai penggunaan Cubicost TRB

Sumber: Penulis, 2019

\begin{tabular}{|c|c|c|c|c|}
\hline \multicolumn{5}{|c|}{ Cubicost TRB } \\
\hline Responden & $\begin{array}{c}\text { Akurasi } \\
\text { Perhitungan }\end{array}$ & $\begin{array}{c}\text { Kebutuhan } \\
\text { Waktu Kerja }\end{array}$ & $\begin{array}{c}\text { Cara } \\
\text { Pengoperasian }\end{array}$ & \multirow[t]{2}{*}{ Total } \\
\hline & $44 \%$ & $24 \%$ & $32 \%$ & \\
\hline & (A) & (B) & (C) & $\begin{array}{l}(\mathrm{A} \times 44 \%)+(\text { B } \times 24 \%)+(\mathrm{C} \times \\
32 \%)\end{array}$ \\
\hline Y1 & 9 & 8 & 9 & 8.76 \\
\hline Y2 & 9 & 7 & 8 & 8.2 \\
\hline Y3 & 7 & 7 & 8 & 7.32 \\
\hline Y4 & 8 & 8 & 8 & 8 \\
\hline Y5 & 9 & 8 & 6 & 7.8 \\
\hline Y6 & 9 & 9 & 8 & 8.68 \\
\hline Y7 & 8 & 10 & 8 & 8.48 \\
\hline Y8 & 9 & 9 & 8 & 8.68 \\
\hline Y9 & 9 & 8 & 9 & 8.76 \\
\hline \multirow[t]{3}{*}{ Y10 } & 9 & 8 & 8 & 8.44 \\
\hline & & & Total & 83.1 \\
\hline & & & Rata-rata & 8.31 \\
\hline
\end{tabular}


Tabel 9. Hasil penilaian mengenai penggunaan metode konvensional

Sumber: Penulis, 2019

\begin{tabular}{|c|c|c|c|c|}
\hline \multicolumn{5}{|c|}{ Metode Konvensional } \\
\hline Responden & $\begin{array}{c}\text { Akurasi } \\
\text { Perhitungan }\end{array}$ & $\begin{array}{c}\text { Kebutuhan } \\
\text { Waktu Kerja }\end{array}$ & $\begin{array}{c}\text { Cara } \\
\text { Pengoperasian }\end{array}$ & \multirow[t]{2}{*}{ Total } \\
\hline & $44 \%$ & $24 \%$ & $32 \%$ & \\
\hline & (A) & (B) & (C) & $\begin{array}{l}(\mathrm{A} \times 44 \%)+(\mathrm{B} \times 24 \%)+(\mathrm{C} \times \\
32 \%)\end{array}$ \\
\hline Y1 & 6 & 6 & 6 & 6 \\
\hline $\mathrm{Y} 2$ & 6 & 7 & 9 & 7.2 \\
\hline Y3 & 7 & 3 & 3 & 4.76 \\
\hline $\mathrm{Y} 4$ & 8 & 6 & 7 & 7.2 \\
\hline Y5 & 7 & 7 & 8 & 7.32 \\
\hline Y6 & 8 & 6 & 9 & 7.84 \\
\hline Y7 & 7 & 7 & 7 & 7 \\
\hline Y8 & 7 & 7 & 7 & 7 \\
\hline Y9 & 7 & 6 & 4 & 5.8 \\
\hline \multirow[t]{3}{*}{ Y10 } & 8 & 8 & 8 & 8 \\
\hline & & & Total & 68.1 \\
\hline & & & Rata-rata & 6.81 \\
\hline
\end{tabular}

Berdasarkan hasil dari kuesioner di atas dapat disimpulkan bahwa lebih mundah menggunakan Cubicost TRB dibandingkan dengan metode konvensional. Nilai rata-rata keseluruhan yang diperoleh untuk pekerjaan quantity take off besi dengan menggunakan Cubicost TRB adalah 8,31 dan dengan metode konvensional adalah 6,81. Grafik di bawah ini menunjukkan nilai rata-rata untuk masing-masing identifikasi yang ditinjau, antara lain akurasi perhitungan, kebutuhan waktu kerja dan cara pengoperasian.

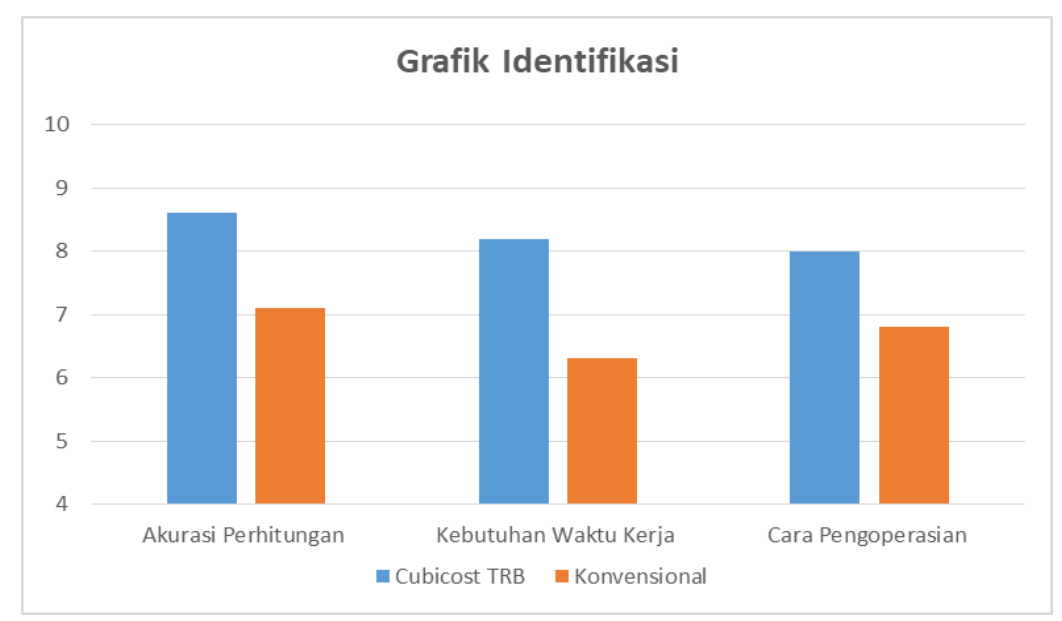

Gambar 1. Grafik identifikasi

Sumber: Penulis, 2019

Grafik identifikasi menunjukkan bahwa masing-masing klasifikasi didominasi dengan penggunaan Cubicost TRB dikatakan lebih mudah. Hal ini dapat disimpulkan, berdasarkan pengguna Cubicost TRB untuk pekerjaan quantity take off besi pada proses tender di PT XYZ bahwa menggunakan Cubicost TRB dianggap lebih mudah dibandingkan dengan menggunakan metode konvensional. 


\section{KESIMPULAN dan SARAN}

\section{Kesimpulan}

1. Prosedur kerja pada penelitian ini mengenai pekerjaan quantity take off besi pada PT XYZ dapat dijadikan standar agar timbul keseragaman dalam melakukan pekerjaan quantity take off. Terdapat 10 langkah kerja untuk pekerjaan quantity take off besi dengan menggunakan Cubicost TRB dan 13 langkah kerja untuk metode konvensional.

2. Kebutuhan waktu pekerjaan quantity take off besi dengan menggunakan Cubicost TRB lebih cepat 58\% dibandingkan dengan menggunakan metode konvensional.

3. Ditemukan perbandingan hasil kebutuhan besi dengan menggunakan Cubicost TRB dan metode konvensional. Perbedaan persentase kebutuhan besi dan faktor penyebabnya antara lain:

a. Perhitungan kebutuhan besi pada kolom basement dengan menggunakan Cubicost TRB lebih besar 4,2\% daripada menggunakan metode konvensional. Penyebabnya adalah jumlah sengkang yang berbeda dan jumlah tulangan utama kolom yang masuk ke dalam pilecap/raft tidak dapat diatur

b. Perhitungan kebutuhan besi pada kolom dengan menggunakan Cubicost TRB lebih besar 3,44\% dibandingkan dengan menggunakan metode konvensional. Penyebabnya adalah jumlah sengkang yang dihitung menggunakan Cubicost TRB lebih banyak

c. Perhitungan kebutuhan besi pada balok dengan menggunakan Cubicost TRB lebih besar $0,71 \%$ dibandingkan dengan menggunakan metode konvensional. Penyebabnya adalah terdapat perbedaan panjang tulangan utama yang memiliki perbedaan dimensi dengan balok di sampingnya. Perhitungan dengan menggunakan Cubicost TRB lebih detail dan menyesuaikan standar detail perhitungan.

d. Perhitungan kebutuhan besi pada pelat lantai dengan menggunakan Cubicost TRB lebih besar $1,4 \%$ dibandingkan dengan menggunakan metode konvensional. Penyebabnya adalah terdapat perbedaan jumlah tulangan pelat lantai yang menerus arah X dan Y.

4. Terdapat 21 keunggulan dan 9 kendala yang ada pada Cubicost TRB dalam pekerjaan quantity take off besi pada proses tender. Tampilan Cubicost TRB mudah dipahami, karena dilengkapi dengan tampilan 3D dan terdapat keterangan untuk penggunaan masing-masing tools. Kendala yang paling signifikan dirasakan oleh pengguna Cubicost TRB adalah tidak semua standar detail konsultan struktur perencana yang ada di Indonesia dapat diserap oleh Cubicost TRB.

5. Terdapat tiga klasifikasi kebutuhan yang diperlukan pada pekerjaan quantity take off besi pada proses tender, yaitu kebutuhan waktu kerja, akurasi perhitungan dan cara pengoperasian. Dari analisis pairwise comparison yang dilakukan ketiga klasifikasi ini memiliki bobot yang berbeda-beda, antara lain secara berurutan $24 \%$, $44 \%$ dan $32 \%$. Berdasarkan penilaian dengan skala 1-10 dari penggunaan Cubicost TRB dan metode konvensional diperoleh nilai rata-rata sebesar 8,31 untuk Cubicost TRB dan 6,81 untuk metode konvensional. Pekerjaan quantity take off dengan menggunakan Cubicost TRB lebih cepat, lebih akurat dan pengoperasiannya lebih mudah dibandingkan dengan metode konvensional.

\section{Saran}

Berdasarkan hasil penelitian ini, sebaiknya cara perhitungan yang tidak dapat diserap oleh Cubicost TRB dapat dikombinasikan dengan penggunaan metode konvensional (MS. Excel), sebagai contoh adalah perhitungan tangga, ramp dan sumpit. Penelitian ini juga perlu tambahan untuk responden yang paham mengenai penggunaan Cubicost TRB, disarankan penelitian 
lanjutan untuk melakukan pembahasan mengenai software Cubicost lainnya, yaitu TAS, TME dan TBQ guna mempermudah bidang lain dalam pekerjaan quantity take off.

\section{REFERENSI}

Azhar, S. (2011). "Building Information Modelling (BIM): Trends, Benefits, Risks, and Challenges for the AEC Industry". Leadership Manage 2011, page 241-252.

Al-Anbari, M., dan Thameer, M.Y. (2015). "Landfill Site Selection by Using Pairwise Comparison, Rating, Ranking and Trade-off Methods for Criteria Weighting". International Journal of Civil Engineering and Technology (IJCIET), Vol 6, Issue 11, Nov 2015, pp. 111-125, IAEME Publication.

Hallowell, M.R., dan Gambatase, J.A. (2010). "Qualitative research: application of the Delphi method to CEM research”. J. Constr Eng Manage ASCE, 136(1): 99-107.

LeBreton, J. M., \& Senter, J. L. (2008). "Answers to 20 questions about interrater reliability and interrater agreement”. Organizational Research Methods, 11(4), 815-852.

Linestone, H. dan Turoff, M. (1975). The Delphi Method: Techniques and Aplications. Mass: Addison-Wesley, Reading.

Lu, W. dkk. (2013). "Generic Model for Measuring Benefits of BIM as a Learning Tool in Construction Tasks". J. Constr. Eng. Manage ACSE, 139(2): 195-203.

Saaty, T.L. (1980). "The Analytic Hierarchy Process”. New York: McGraw Hill. International, Revised editions, RWS Publications, Pittsburgh.

Saaty, T.L. (2008). "Decision making with the analytic hierarchy process". Int. J. Services Sciences, Vol. 1, No. 1, pp.83-98.

Seyis, Senem. (2019). "Pros and Cons of Using Building Information Modelling in the AEC Industry”. J. Constr. Eng. Manage., 145(8): 04019046.

Susanto, A. (2012). Perhitungan Besi Estimate TBP, Departemen Estimate Total BP,Jakarta. 
